\title{
Erlotinib as salvage treatment after failure to first-line gefitinib in non-small cell lung cancer
}

\author{
Matthew K. Wong $\cdot$ Alvis I. Lo $\cdot$ Bing Lam $\cdot$ \\ W. K. Lam · Mary S. Ip · James C. Ho
}

Received: 17 June 2009/ Accepted: 30 July 2009/Published online: 13 August 2009

(C) Springer-Verlag 2009

\begin{abstract}
Purpose Chemotherapy is the mainstay treatment for advanced non-small cell lung cancer (NSCLC). Gefitinib, an epidermal growth factor receptor-tyrosine kinase inhibitor (EGFR-TKI), has been recently shown to be effective as a first-line treatment in Asian patients with advanced NSCLC, especially for those with favourable clinical features such as female, non-smoker and adenocarcinoma. However, resistance to gefitinib ensues invariably and there is little evidence as for the effectiveness of subsequent salvage treatment. The purpose of this study is to evaluate the efficacy of erlotinib, another EGFR-TKI, after failed first-line use of gefitinib.

Method Retrospective review of NSCLC patients with favourable clinical features who received gefitinib as firstline treatment and subsequent salvage treatment with erlotinib.

Results A total of 21 patients with NSCLC were included in the study. Among them, 18 (85.7\%) patients had disease control with gefitinib and $12(57.1 \%)$ patients with salvage erlotinib. There was an association between the disease control with gefitinib and erlotinib $(p=0.031)$. The disease control rate of erlotinib was independent of the chemotherapy use between the two EGFR-TKIs.
\end{abstract}

M. K. Wong · A. I. Lo · B. Lam · W. K. Lam

M. S. Ip · J. C. Ho $(\bowtie)$

Division of Respiratory Medicine,

Department of Medicine, The University of Hong Kong,

Queen Mary Hospital, Hong Kong, China

e-mail: jhocm@hkucc.hku.hk

A. I. Lo

Department of Respiratory Medicine,

Centro Hospital Conde de Sao Januario, Macau, China
Conclusion For NSCLC patients with favourable clinical features, erlotinib was effective in those who had prior disease control with first-line gefitinib.

Keywords Non-small cell lung cancer · Gefitinib .

Erlotinib - Epidermal growth factor

receptor tyrosine kinase inhibitors - Asians .

Disease control rate

\section{Introduction}

Lung cancer, predominantly non-small cell carcinoma (NSCLC), has been a major cause of cancer deaths worldwide [1] mostly related to its advanced stages upon presentation. Platinum-based chemotherapy has become the mainstay systemic treatment for advanced NSCLC with modest improvement in overall survival and quality of life [2], at the expense of moderate to severe toxicities [3]. In recent years, selective epidermal growth factor receptor tyrosine kinase inhibitor (EGFR-TKI) has emerged as an alternative treatment option for advanced NSCLC with distinct mechanism of action and safety profile. Both erlotinib and gefitinib, as prototypes of EGFR-TKI, have demonstrated clinical efficacy in the second- or third-line treatment of NSCLC, especially among never-smokers, females, East Asians, and adenocarcinoma cell type. [4-7].

With the favourable toxicity profile of EGFR-TKI, there have been great interests to bring it upfront in the first-line treatment of advanced NSCLC. Gefitinib used in the firstline setting has been reported with promising results in Asian countries $[8,9]$. Moreover, a multicentre phase III randomised clinical trial has recently suggested that gefitinib might be a good option for first-line treatment of 
adenocarcinoma of lung in non-smoking Asians, with superior clinical efficacy and tolerability compared to standard chemotherapy [10]. However, subsequent resistance to gefitinib is inevitable even among the initial good responders, mostly related to acquired EGFR mutation (T790M) or c-met amplification [11, 12].

Large-scale phase III clinical trials have demonstrated survival benefit with erlotinib but not gefitinib as secondor third-line treatment of advanced NSCLC, suggesting pharmacological differences between the two EGFR-TKIs $[4,7]$. It would be logical to try erlotinib in case of gefitinib failure, especially among those highly selected patient population with anticipated favourable response to EGFR inhibition. Therefore, we conducted a retrospective review of our single institutional experience of salvage erlotinib treatment in patients with advanced NSCLC after failure to first-line gefitinib.

\section{Materials and methods}

\section{Patient identification and data collection}

Eligible patients, all Chinese, had histologically or cytologically confirmed NSCLC who received treatment with gefitinib as first-line and erlotinib as subsequent salvage therapy from January 2004 to December 2008 in the Department of Medicine at Queen Mary Hospital, an University-affiliated teaching hospital in Hong Kong. Clinical data were collected retrospectively, including age, sex, performance status on diagnosis (Eastern Cooperative Oncology Group performance status [ECOG PS]), smoking history, staging of disease, EGFR mutation, systemic chemotherapy, radiotherapy, best overall tumour responses, gefitinib or erlotinib-related adverse reactions, reasons of stopping EGFR-TKI, and mortality until 31st December 2008. The study protocol was approved by the Institutional Review Board of the University of Hong Kong/Hospital Authority Hong Kong West Cluster and conducted according to the Declaration of Helsinki. The primary aim was to assess the disease control rates of patients who received erlotinib in the salvage setting after failure to firstline gefitinib. The secondary outcome was to identify predicting factors for response to salvage treatment with erlotinib.

\section{Response evaluation}

According to institutional practice, all patients were regularly followed up every 4 weeks ( \pm 1 week) with imaging studies (chest X-ray or computed tomography [CT] where appropriate) during treatment with EGFR-TKIs. The best overall tumour responses (complete response [CR], partial response [PR], stable disease [SD] and progressive disease $[\mathrm{PD}])$ during the course of different treatment modalities were based on review of medical records and imaging studies available, according to RECIST criteria [13]. In the case of stable disease, measurements must have met the stable disease criteria at least once after study entry at a minimum interval (in general, not less than 6-8 weeks) [13]. Responses to EGFR-TKIs were evaluated at least 4 weeks after the initiation of treatment. Disease control (DC) was defined as a lack of PD and clinical improvement or stability, as assessed by the attending physicians, and continuation of drug treatment for at least 8 weeks. The treatment with EGFR-TKIs would be stopped at the time of documented worsening of existing lesions or emergence of new lesions, which was regarded as PD. Overall survival was evaluated from the initiation of gefitinib therapy to the date of death or study cut-off on 31st December 2008.

Toxicity evaluation

Toxicity profile of EGFR-TKI was assessed by reviewing medical records, including skin rash, diarrhoea, liver toxicity, and radiological evidence of interstitial pneumonitis. Severity of adverse reactions was determined according to the need of dosage reduction or discontinuation of EGFRTKI.

Statistical analysis

Continuous data were expressed as mean \pm SD and categorical data were expressed as percentage. Comparisons between two groups were performed with Student's $t$-test for continuous variables and Fisher's exact test for categorical variables. The relationship between the disease control rate of gefitinib and erlotinib was explored using McNemar's test. Survival analysis was conducted with Kaplan Meier analysis and log-rank test. A $p$-value of less than 0.05 was considered significant. All statistical tests were conducted using the computer software SPSS version 16.0 (SPSS Inc., Chicago, IL, USA).

\section{Results}

Clinical and epidemiological characteristics

Sixty-eight patients with NSCLC who received both gefitinib and erlotinib were screened. Twenty-one Chinese patients (19 women; mean age $67.9 \pm 8.1$ years) received gefitinib as the first-line treatment and erlotinib as salvage therapy, with or without systemic chemotherapy in between the EGFR-TKIs. All of them were never smokers except one who had quitted for 40 years with less than 10 
pack-years of smoking. The majority of the tumours were adenocarcinoma $(90 \%)$ and in advanced stage $(61.9 \%$ stage IV) on presentation. EGFR mutation tests were available in four patients, in whom three of them were positive for point mutation in exon 21 (L858R and L861Q) and one was negative. At the time of initiation of gefitinib treatment, most of the patients were in good performance status ( $>90 \%$ in ECOG 0 or 1). Gefitinib was prescribed at standard dosage of $250 \mathrm{mg}$ daily and erlotinib at $150 \mathrm{mg}$ daily. Erlotinib was used as second-line treatment in 13 (62\%) patients immediately after failure to gefitinib (Table 1).

\section{Tumour response}

Disease control was achieved in 18 patients $(85.7 \%)$ and 12 patients $(57.1 \%)$ with gefitinib and erlotinib as first-line

Table 1 Characteristics of 21 Chinese patients with non-small cell lung cancer (NSCLC) treated with gefitinib as first-line and erlotinib as salvage therapy

\begin{tabular}{|c|c|c|}
\hline Characteristic & $n$ & $\%$ \\
\hline \multicolumn{3}{|l|}{ Age, years } \\
\hline Mean \pm SD & $67.9 \pm 8.1$ & \\
\hline Range & $50-83$ & \\
\hline \multicolumn{3}{|l|}{ Sex } \\
\hline Female & 19 & 90.5 \\
\hline Male & 2 & 9.5 \\
\hline \multicolumn{3}{|l|}{ Smoking history } \\
\hline Never smoker & 20 & 95.2 \\
\hline Ex-light smoker & 1 & 4.8 \\
\hline \multicolumn{3}{|l|}{ Cell type } \\
\hline Adenocarcinoma & 19 & 90.4 \\
\hline Large cell carcinoma & 1 & 4.8 \\
\hline NSCLC & 1 & 4.8 \\
\hline \multicolumn{3}{|l|}{ EGFR mutation } \\
\hline Not done & 17 & 80.9 \\
\hline Positive & 3 & 14.3 \\
\hline Negative & 1 & 4.8 \\
\hline \multicolumn{3}{|l|}{ Stage } \\
\hline IIIb & 8 & 38.1 \\
\hline IV & 13 & 61.9 \\
\hline \multicolumn{3}{|c|}{ ECOG performance status } \\
\hline 0 & 6 & 28.6 \\
\hline 1 & 13 & 61.9 \\
\hline 2 & 2 & 9.5 \\
\hline \multicolumn{3}{|c|}{ Chemotherapy between two EGFR-TKIs } \\
\hline Yes & 8 & 38.1 \\
\hline No & 13 & 61.9 \\
\hline
\end{tabular}

$E G F R$ epidermal growth factor receptor, ECOG Eastern Cooperative Oncology Group, TKI tyrosine kinase inhibitor

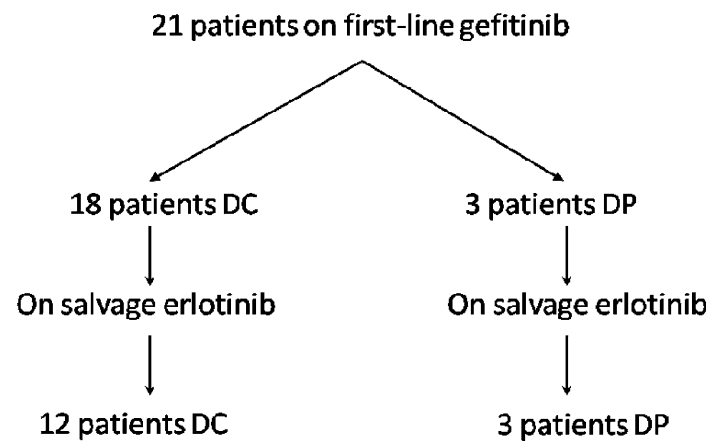

Fig. 1 Relationship between disease control to gefitinib and erlotinib. There was significant association between the occurrence of disease control to gefitinib and that to erlotinib (McNemar test $p=0.031$ ). $D C$ disease control, $D P$ disease progression

and salvage therapy, respectively. All the 12 patients who achieved disease control with erlotinib were having SD as their best response. There is a significant association between the occurrence of disease control to gefitinib in the first-line and that to erlotinib as salvage treatment $(p=0.031$, Fig. 1$)$. For those 18 patients who had prior disease control with gefitinib, 12 patients $(66.7 \%)$ attained disease control with erlotinib. For those three patients whose disease could not be controlled with gefitinib, all of them did not respond to erlotinib. The disease control with erlotinib was independent of age, gender, duration of gefitinib treatment and the use of chemotherapy between the two EGFR-TKIs. The median overall survival of this group was 25.2 months (interquartile range 29.6 months). Five patients $(23.8 \%)$ received chemotherapy after the failure of the two EGFR-TKIs. Four of them had progressive disease shortly after 1-4 courses of chemotherapy (pemetrexed $[n=2]$, gemcitabine/carboplatin/bevacizumab $[n=1]$, sequential docetaxel and gemcitabine $[n=1]$ ) and the remaining one had partial response to six cycles of gemcitabine/carboplatin doublet. Patients were found to have significantly shorter overall survival if disease control could not be achieved with the use of erlotinib as salvage therapy, 10.3 versus 40.0 months ( $p=0.002$, Fig. 2). The median progression-free survival for gefitinib and erlotinib was 23.7 weeks (interquartile range 31.5 weeks) and 14.9 weeks (interquartile range 16.1 weeks), respectively (Fig. 3).

\section{Toxicity}

One patient had gefitinib withheld for 1.5 months because of skin toxicity and subsequently tolerated well after resumption until disease progression. She had no adverse reaction with the subsequent use of erlotinib. None of the patients had treatment terminated because of severe toxicity from EGFR-TKIs. 


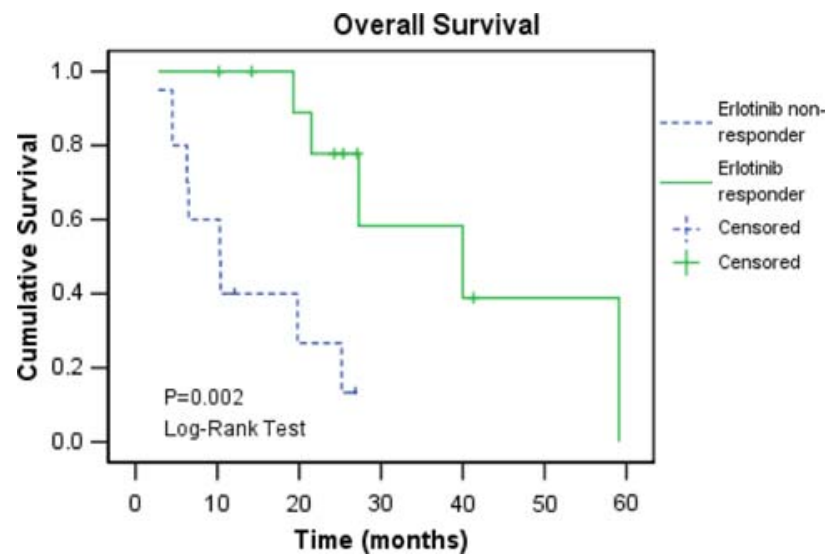

Fig. 2 Kaplan-Meier plot of overall survival. Median survival was 40.0 months (95\% confidence interval: 13.6-66.4) for erlotinib responder and 10.3 months (95\% confidence interval: 4.26-16.3) for erlotinib non-responder $(p=0.002)$

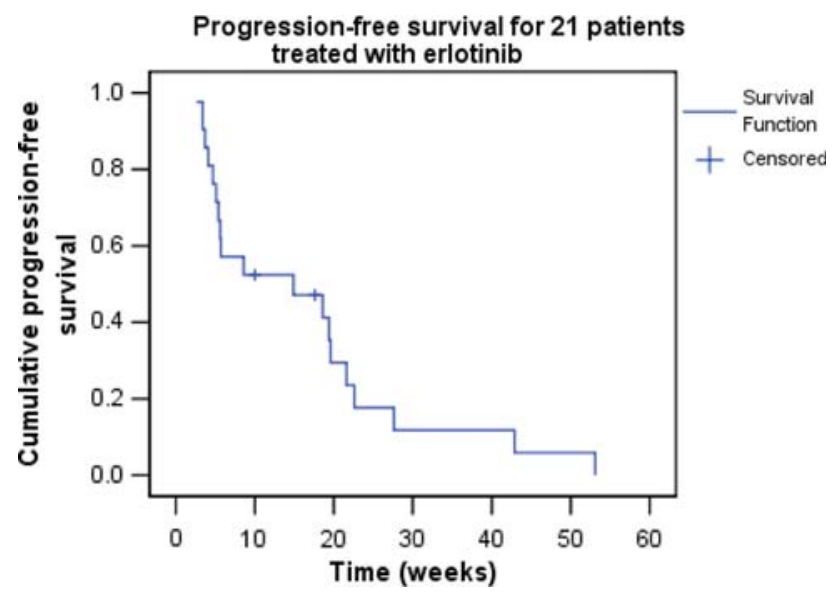

Fig. 3 Kaplan-Meier plot of progression-free survival with a median of 14.9 weeks for patients treated with salvage erlotinib

\section{Discussion}

Although recent clinical trials have provided emerging evidence for gefitinib as first-line treatment for patients with NSCLC, there is a lack of clinical data exploring the role of erlotinib as subsequent therapy after failure to gefitinib. In this retrospective study of a highly selected subgroup (Chinese, nonsmokers, adenocarcinoma and females) of advanced NSCLC who responded favourably to gefitinib in the first-line setting, salvage treatment with erlotinib could attain a disease control rate of $66.7 \%$, though only stable disease was achieved as the best overall response. Most patients (ECOG 0 or 1 in $>90 \%$ ) in the current study were suitable candidates for systemic chemotherapy as an alternative first-line treatment. Nonetheless, based on the promising results from recent trials, gefitinib would undoubtedly be considered as a superior first-line treatment for advanced NSCLC in patients with favourable clinical variables (Asian ethnicity, non-smoker or ex-light smoker, adenocarinoma and female) or presence of sensitising EGFR mutations in tumour samples [8-10]. Therefore, the encouraging result of salvage erlotinib after failure to first-line gefitinib in advanced NSCLC would certainly be of clinical interest.

The exceptionally high disease control rate of first-line treatment with gefitinib (85.7\%) in our study is likely to be related to selection bias in a non-trial setting. In clinical practice, gefitinib is mostly chosen to be the first-line treatment in an enriched patient population with favourable predictors for good response, preferably including EGFR sensitising mutations. One of the limiting factors for testing EGFR mutation status is the lack of tissue availability. EGFR was only tested in $20 \%$ of our patients as it was not considered as a prerequisite during the study period and the aforementioned clinical variables would provide a close approximation. Although there was a lack of clinical data to support the use of erlotinib as a salvage treatment after failure to first-line gefitinib, this approach of treatment was mostly adopted for patients who had demonstrated good response to previous gefitinib treatment. Otherwise, alternative treatment approach with systemic chemotherapy or best supportive care would be offered. Interestingly, in this highly selected NSCLC patient population with prior disease control from gefitinib, subsequent treatment with the same class of targeted therapy, namely erlotinib, could also result in disease control in $66.7 \%(12 / 18)$ of patients. The use of chemotherapy before treatment with erlotinib, or the presence of "EGFR-TKI-free" period, apparently was not a pre-requisite for response to salvage erlotinib treatment in our study cohort.

Ever since the first report of a patient with advanced NSCLC who responded to erlotinib after failure of gefitinib, there have been several anecdotal case reports [14-18], retrospective case series [19-21] and three phase II clinical trials [22-24] on this approach with conflicting results. Most of the case series and clinical trials reported the experience of using gefitinib in the second- or third-line setting, with erlotinib being used in at least the third-line setting. Two phase II clinical trials on advanced NSCLC have reported encouraging disease control rates (28.6 and $62.5 \%$ ) with the use of salvage erlotinib in patients with previously high disease control rates to gefitinib (47.6 and $100 \%$, respectively) [23, 24]. However, another phase II clinical trial has only demonstrated a disease control rate of $8.7 \%$ with salvage erlotinib despite previous good response to gefitinib (disease control rate $73.9 \%$ ) [22]. Heterogeneity of the study populations might account for the conflicting results.

An acquired EGFR mutation (T790M) has been reported to occur upon failure of gefitinib and is also predictive of resistance to erlotinib [11, 25]. However, the acquired 
resistance is not completely explained by the T790M mutation in all cases [26]. The presence of heterogenous malignant clones with different EGFR mutation status may confer differential sensitivity to the two EGFR-TKIs [27]. Also, the different treatment efficacy between the two EGFR-TKIs has been proposed to be related to drug pharmacokinetics [28], with gefitinib given at largely submaximal tolerated dose (MTD) in contrast to erlotinib at MTD. Erlotinib is less susceptible than gefitinib to metabolism by the cytochrome-P450 pathway with lower clearance rate, thus able to inhibit the activity of wild-type EGFR at lower concentration than gefitinib [29, 30]. Loss of acquired resistance after a significant "TKI-free intervals" or chemotherapy given during the TKI free interval can also potentially result in reduction of TKI-resistant clones [31].

In conclusion, erlotinib might be considered as a salvage treatment for highly selected patients with advanced NSCLC who demonstrated initial disease control with firstline gefitinib, irrespective of the use of chemotherapy in between the two EGFR-TKIs. A large prospective randomized control trial, with EGFR mutation studies, is warranted to confirm our observations.

Acknowledgment There is no grant support for this study.

\section{References}

1. Jemal A, Siegel R, Ward E, Murray T, Xu J, Smigal C, Thun MJ (2006) Cancer statistics, 2006. CA Cancer J Clin 56:106-130

2. Non-small Cell Lung Cancer Collaborative Group (1995) Chemotherapy in non-small cell lung cancer: a meta-analysis using updated data on individual patients from 52 randomised clinical trials. Nonsmall Cell Lung Cancer Collaborative Group. BMJ 311:899-909

3. Schiller JH, Harrington D, Belani CP, Langer C, Sandler A, Krook J, Zhu J, Johnson DH (2002) Comparison of four chemotherapy regimens for advanced non-small-cell lung cancer. $\mathrm{N}$ Engl J Med 346:92-98

4. Thatcher N, Chang A, Parikh P, Rodrigues Pereira J, Ciuleanu T, von Pawel J, Thongprasert S, Tan EH, Pemberton K, Archer V, Carroll K (2005) Gefitinib plus best supportive care in previously treated patients with refractory advanced non-small-cell lung cancer: results from a randomised, placebo-controlled, multicentre study (Iressa Survival Evaluation in Lung Cancer). Lancet 366:1527-1537

5. Fukuoka M, Yano S, Giaccone G, Tamura T, Nakagawa K, Douillard JY, Nishiwaki Y, Vansteenkiste J, Kudoh S, Rischin D, Eek R, Horai T, Noda K, Takata I, Smit E, Averbuch S, Macleod A, Feyereislova A, Dong RP, Baselga J (2003) Multi-institutional randomized phase II trial of gefitinib for previously treated patients with advanced non-small-cell lung cancer (The IDEAL 1 Trial) [corrected]. J Clin Oncol 21:2237-2246

6. Kris MG, Natale RB, Herbst RS, Lynch TJ Jr, Prager D, Belani CP, Schiller JH, Kelly K, Spiridonidis H, Sandler A, Albain KS, Cella D, Wolf MK, Averbuch SD, Ochs JJ, Kay AC (2003) Efficacy of gefitinib, an inhibitor of the epidermal growth factor receptor tyrosine kinase, in symptomatic patients with non-small cell lung cancer: a randomized trial. JAMA 290:2149-2158
7. Bezjak A, Tu D, Seymour L, Clark G, Trajkovic A, Zukin M, Ayoub J, Lago S, de Albuquerque Ribeiro R, Gerogianni A, Cyjon A, Noble J, Laberge F, Chan RT, Fenton D, von Pawel J, Reck M, Shepherd FA (2006) Symptom improvement in lung cancer patients treated with erlotinib: quality of life analysis of the National Cancer Institute of Canada Clinical Trials Group Study BR.21. J Clin Oncol 24:3831-3837

8. Niho S, Kubota K, Goto K, Yoh K, Ohmatsu H, Kakinuma R, Saijo N, Nishiwaki Y (2006) First-line single agent treatment with gefitinib in patients with advanced non-small-cell lung cancer: a phase II study. J Clin Oncol 24:64-69

9. Lee DH, Han JY, Lee HG, Lee JJ, Lee EK, Kim HY, Kim HK, Hong EK, Lee JS (2005) Gefitinib as a first-line therapy of advanced or metastatic adenocarcinoma of the lung in neversmokers. Clin Cancer Res 11:3032-3037

10. Mok T, Wu YL, Thongprasert S, Yang CH, Chu D, Saijo N, Jiang H, Watkins C, Armour A, Fukuoka M (2008) Phase III, randomized, open-label, first-line study of gefitinib versus carboplatin/paclitaxel in clinically selected patients with advanced non-small-cell lung cancer (IPASS). Ann Oncol 19:viii

11. Pao W, Miller VA, Politi KA, Riely GJ, Somwar R, Zakowski MF, Kris MG, Varmus H (2005) Acquired resistance of lung adenocarcinomas to gefitinib or erlotinib is associated with a second mutation in the EGFR kinase domain. PLoS Med 2:e73

12. Pao W, Wang TY, Riely GJ, Miller VA, Pan Q, Ladanyi M, Zakowski MF, Heelan RT, Kris MG, Varmus HE (2005) KRAS mutations and primary resistance of lung adenocarcinomas to gefitinib or erlotinib. PLoS Med 2:e17

13. Therasse P, Arbuck SG, Eisenhauer EA, Wanders J, Kaplan RS, Rubinstein L, Verweij J, Van Glabbeke M, van Oosterom AT, Christian MC, Gwyther SG (2000) New guidelines to evaluate the response to treatment in solid tumors. European Organization for Research and Treatment of Cancer, National Cancer Institute of the United States, National Cancer Institute of Canada. J Natl Cancer Inst 92:205-216

14. Walther JC, Khorshid M, Gaya A, Plowman PN (2006) Crossover response to erlotinib of brain metastatic disease from bronchial adenocarcinoma after gefitinib failure, and an unusual rash. Clin Oncol (R Coll Radiol) 18:637-639

15. Sim SH, Han SW, Oh DY, Lee SH, Kim DW, Im SA, Chung DH, Kim TY, Lee JS, Kim YW, Heo DS, Bang YJ (2008) Erlotinib after Gefitinib failure in female never-smoker Asian patients with pulmonary adenocarcinoma. Lung Cancer. doi:10.1016/ j.lungcan.2008.11.006

16. Chang JW, Chou CL, Huang SF, Wang HM, Hsieh JJ, Hsu T, Cheung YC (2007) Erlotinib response of EGFR-mutant gefitinibresistant non-small-cell lung cancer. Lung Cancer 58:414-417

17. Garfield DH (2005) Modern treatment of lung cancer: case 2. Response to erlotinib after failure of gefitinib in a patient with advanced non-small-cell lung carcinoma. J Clin Oncol 23:77387740

18. Gridelli C, Maione P, Galetta D, Colantuoni G, Del Gaizo F, Ferrara C, Guerriero C, Nicolella D, Rossi A (2007) Three cases of long-lasting tumor control with erlotinib after progression with gefitinib in advanced non-small cell lung cancer. J Thorac Oncol 2:758-761

19. Costa DB, Nguyen KS, Cho BC, Sequist LV, Jackman DM, Riely GJ, Yeap BY, Halmos B, Kim JH, Janne PA, Huberman MS, Pao W, Tenen DG, Kobayashi S (2008) Effects of erlotinib in EGFR mutated non-small cell lung cancers with resistance to gefitinib. Clin Cancer Res 14:7060-7067

20. Viswanathan A, Pillot G, Govindan R (2005) Lack of response to erlotinib after progression on gefitinib in patients with advanced non-small cell lung cancer. Lung Cancer 50:417-418

21. Wong AS, Soong R, Seah SB, Lim SW, Chuah KL, Nga ME, Chin TM, Soo RA (2008) Evidence for disease control with 
erlotinib after gefitinib failure in typical gefitinib-sensitive Asian patients with non-small cell lung cancer. J Thorac Oncol 3:400404

22. Lee DH, Kim SW, Suh C, Yoon DH, Yi EJ, Lee JS (2008) Phase II study of erlotinib as a salvage treatment for non-small-cell lung cancer patients after failure of gefitinib treatment. Ann Oncol 19:2039-2042

23. Cho BC, Im CK, Park MS, Kim SK, Chang J, Park JP, Choi HJ, Kim YJ, Shin SJ, Sohn JH, Kim H, Kim JH (2007) Phase II study of erlotinib in advanced non-small-cell lung cancer after failure of gefitinib. J Clin Oncol 25:2528-2533

24. Vasile E, Tibaldi C, Chella A, Falcone A (2008) Erlotinib after failure of gefitinib in patients with advanced non-small cell lung cancer previously responding to gefitinib. J Thorac Oncol 3:912-914

25. Kobayashi S, Boggon TJ, Dayaram T, Janne PA, Kocher O, Meyerson M, Johnson BE, Eck MJ, Tenen DG, Halmos B (2005) EGFR mutation and resistance of non-small-cell lung cancer to gefitinib. N Engl J Med 352:786-792

26. Kosaka T, Yatabe Y, Endoh H, Yoshida K, Hida T, Tsuboi M, Tada H, Kuwano H, Mitsudomi T (2006) Analysis of epidermal growth factor receptor gene mutation in patients with non-small cell lung cancer and acquired resistance to gefitinib. Clin Cancer Res 12:5764-5769

27. Chou WC, Huang SF, Yeh KY, Wang HM, Liu MY, Hsieh JJ, Cheung YC, Chang JW (2006) Different responses to gefitinib in lung adenocarcinoma coexpressing mutant- and wild-type epidermal growth factor receptor genes. Jpn J Clin Oncol 36:523526

28. Baselga J, Arteaga CL (2005) Critical update and emerging trends in epidermal growth factor receptor targeting in cancer. J Clin Oncol 23:2445-2459

29. Li J, Zhao M, He P, Hidalgo M, Baker SD (2007) Differential metabolism of gefitinib and erlotinib by human cytochrome $\mathrm{P} 450$ enzymes. Clin Cancer Res 13:3731-3737

30. Sharma SV, Bell DW, Settleman J, Haber DA (2007) Epidermal growth factor receptor mutations in lung cancer. Nat Rev Cancer 7:169-181

31. Yokouchi H, Yamazaki K, Kinoshita I, Konishi J, Asahina H, Sukoh N, Harada M, Akie K, Ogura S, Ishida T, Munakata M, Dosaka-Akita H, Isobe H, Nishimura M (2007) Clinical benefit of readministration of gefitinib for initial gefitinib-responders with non-small cell lung cancer. BMC Cancer 7:51 